Objectives: The aims of this study were (1) to compare these two pharmacological approaches, and (2) since it would be very interesting to retrospectively assess severe non-adherence in clinical trials or in large cohort of patients in which only serum samples are usually available, to determine if serum HCQ level cut offs could be established for identification of severe non-adherent patients.

Methods: The HCQ and desethylchloroquine (DCQ) levels were measured in serum and whole blood from 573 SLE patients. The risk factors for active SLE (SLEDAI score >4) were identified using multiple logistic regression. $\mathrm{HCQ}$ serum level was also measured in 51 non-adherent patients (whole blood $\mathrm{HCQ}$ level $<200 \mathrm{ng} / \mathrm{mL}$ ).

Results: The mean HCQ and DCQ levels were $916 \pm 449$ and $116 \pm$ $55 \mathrm{ng} / \mathrm{mL}$ in whole blood, respectively; and $469 \pm 223$ and $63 \pm 31 \mathrm{ng} /$ $\mathrm{mL}$ in serum, respectively. The mean ratio of serum/whole blood level for $\mathrm{HCQ}$ and $\mathrm{DCQ}$ were $0.53 \pm 0.15$ and $0.57 \pm 0.21$, respectively. $\mathrm{A}$ strong positive correlation was found between serum and whole blood levels of $\mathrm{HCQ}$ (rho=0.837 [Cl95\% 0.810-0.860], $\mathrm{p}<0.0001$ ), and $\mathrm{DCQ}$ (rho=0.771 [Cl95\% 0.736-0.802], $\mathrm{p}<0.0001)$. In the multivariate analysis, only corticosteroids $(p=0.044)$, immunosuppressant $(p=0.027), \mathrm{HCQ}$ whole blood level $(p=0.023)$ and hemoglobin $(p=0.009)$ were identified as an independent risk factor of active SLE but serum HCQ level was not. Given the mean ratio of serum/whole blood level for $\mathrm{HCQ}$ was 0.53 , we extrapolated that serum $\mathrm{HCQ}$ level cut offs of 106 and $53 \mathrm{ng} / \mathrm{mL}$ would correspond to the previously used cut-off of 200 and $100 \mathrm{ng} / \mathrm{mL}$ of $\mathrm{HCQ}$ in whole blood.

Using $\mathrm{HCQ}$ serum level cut off of $106 \mathrm{ng} / \mathrm{mL}, 43$ of 51 patients $(84 \%)$ with blood $\mathrm{HCQ}$ levels $<200 \mathrm{ng} / \mathrm{mL}$ would also have been considered as non-adherent. The positive and negative predictive value of $\mathrm{HCQ}$ serum level < $106 \mathrm{ng} / \mathrm{ml}$ to detect non-adherence were $96.6 \%$ and $63.6 \%$, respectively.

Of these 51 patients, 25 patients (49\%) exhibited $\mathrm{HCQ}$ whole blood concentration below $100 \mathrm{ng} / \mathrm{mL}$. Using $\mathrm{HCQ}$ serum level cut off of $53 \mathrm{ng} /$ $\mathrm{mL}, 23$ of 25 patients (92\%) with $\mathrm{HCQ}$ whole blood level $<100 \mathrm{ng} / \mathrm{mL}$, would also have been considered as non-adherent. The positive and negative predictive value of $\mathrm{HCQ}$ serum level $<53 \mathrm{ng} / \mathrm{ml}$ to detect nonadherence were $82.1 \%$ and $90.9 \%$.

Conclusion: Our data support the use of whole blood rather than serum as the matrix for drug monitoring of HCQ levels in SLE patients. However, when whole blood is not available, our results support the use of $\mathrm{HCQ}$ serum level to assess non-adherence with a cut off of $106 \mathrm{ng} / \mathrm{mL}$ corresponding to $200 \mathrm{ng} / \mathrm{ml}$ in whole blood.

Disclosure of Interests: None declared

DOI: 10.1136/annrheumdis-2019-eular.4215

\section{SAT0189 A NOVEL DEVICE FOR RAPID MINOR SALIVARY GLAND BIOPSY IN SUSPECTED SJÖGREN'S SYNDROME}

Alexandre Dumusc $^{1}$, Bettina Bannert ${ }^{2}$, Diana Dan ${ }^{1}$, Thomas Huegle ${ }^{1} .{ }^{1}$ University Hospital Lausanne (CHUV), Rheumatology, Lausanne, Switzerland; ${ }^{2}$ Basel University Hospital (USB), Rheumatology, Basel, Switzerland

Background: Labial minor salivary glands (MSG) biopsies are a frequently performed diagnostic procedure for Sjögren's syndrome. MSG biopsy usually requires additional assistance e.g. to provide lower lip protrusion and to apply pressure on the lip during the procedure. The latter is done to foster protrusion of salivary glands and therefore to reduce the incision depth and potential nerve damage. We recently developed a new singleuse device for MSG by 3D-printing in form of a lip clamp with a stamp on the lower arm to reduce invasiveness and to facilitate the intervention.

Objectives: To assess practicability and to describe the technical application of this device for MSG biopsies in the rheumatology department

Methods: Retrospective study of MSG biopsies performed with the use of a dedicated lip clamp. For each MSG biopsy, we recorded if any assistance was needed during the procedure, occurrence of any complication, if salivary glands were obtained and if the quality of the salivary gland tissue sample was adequate for histologic analysis.

Results: 12 MSG biopsies performed on 12 patients with suspected Sjögren's syndrome were included in the study. MSG biopsies were performed between August 2018 and January 2019. Using the lip clamp, the physician was able to perform all the biopsies without assistance. No complication occurred with a follow-up of 1 week for each patient. Salivary glands tissue samples were obtained in $11 / 12$ of the patients using 1 incision. For 1 patient, a second incision had to be performed on the contralateral side of the lip during the same intervention because no glands were found on the first attempt. Quality of all the samples was adequate for histologic analysis. We did not observe an increase in procedure time compared to routine MSG biopsy procedure.

Conclusion: The use of a single-use lip clamp facilitates MSG biopsy without needing assistance and potentially reduces invasiveness and collateral damage. Quality of the tissue samples obtained was adequate for histological analysis.
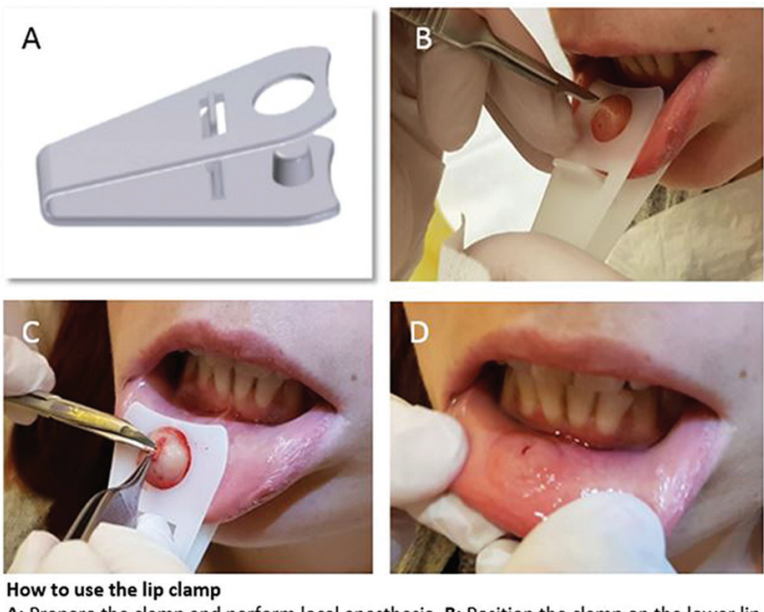

clamp on the lower lip with the recess of the clamp facing up, at $0.5-1 \mathrm{~cm}$ off the midline. C: Perform a $5 \mathrm{~mm}$ vertical superficial incision. Due to the pressure from below, a minor salivary gland vertical superficial incision. Due to the pressure from below, a minor salivary gland
appears. Seize it with forceps and cut it with scissors or scalpel. D: Open and remove the clamp. No stiches are required.

Disclosure of Interests: Alexandre Dumusc: None declared, Bettina Bannert: None declared, Diana Dan: None declared, Thomas Huegle Grant research support from: AbbVie, Lilly, Novartis and Pfizer, Speakers bureau: AbbVie, Lilly, Novartis and Pfizer

DOI: 10.1136/annrheumdis-2019-eular.5974

\section{SAT0190 LYMPHOMA IN PRIMARY SJÖGREN'S SYNDROME: A RETROSPECTIVE CLINICAL STUDY WITH PATIENTS FROM THE UPA (UDINE, PISA, ATHENS) GROUP}

Andreas Goules ${ }^{1}$, Chiara Baldini ${ }^{2}$, Saviana Gandolfo ${ }^{3}$, Aristea Papageorgiou ${ }^{4}$, Dimitris Ziogas ${ }^{4}$, Francesco Ferro ${ }^{2}$, Valentina Donati ${ }^{2}$, Cathryn Scott ${ }^{3}$, Salvatore De Vita ${ }^{3}$, Michael Voulgarelis ${ }^{4}$, Athanasios Tzioufas ${ }^{5} .{ }^{1}$ Athens School of Medicine, National and Kapodistrian University of Athens, Athens, Greece., Pathophysiology, Athens, Greece; ${ }^{2}$ University of Pisa, Rheumatology Unit, Department of Clinical and Experimental Medicine, Pisa, Italy; ${ }^{3}$ University of Udine, Department of Medical and Biological Sciences, Rheumatology Clinic, Udine, Italy; ${ }^{4}$ Athens School of Medicine, National and Kapodistrian University of Athens, Athens, Greece., Pathophysiology, Athens, Greece; ${ }^{5}$ Athens School of Medicine, National and Kapodistrian University of Athens, Athens, Greece., Pahtophysiology, Athens, Greece

Background: Lymphoma development in Sjögren's syndrome has significant impact on morbidity and mortality of the disease.

Objectives: To describe and compare clinical, serological and histological features of patients with primary Sjögren's syndrome (pSS) associated non-Hodgkin's lymphomas (NHLs) in 3 cohorts, from Greece (1) and Italy (2).

Methods: 140 consecutive pSS patients with NHLs who fulfilled the 2002 AECG criteria for Sjögren's were included in the study. Patients were recruited from 3 centers (Udine, Pisa, Athens, cohort named UPA), two from Italy (Udine and Pisa University Hospitals with a total of 63 cases, named cohort UP) and one from Greece (University of Athens with 77 cases, named cohort $\mathrm{A}$ ). Age at $\mathrm{NHL}$ onset, $\mathrm{NHL}$ subtype and distribution, SS disease duration until lymphoma development, serum anti-SSA SSB antibodies and rheumatoid factor, history of salivary gland enlargement, cryoglobulinemia with or without vasculitis and $\mathrm{C} 4$ hypocomplementemia before the onset of $\mathrm{NHL}$ were recorded and compared.

Results: The Greek cohort (A) had a median age at lymphoma diagnosis 58 years (range: $28-90$ years) and the (UP) cohort a median age a diagnosis of lymphoma 55.6 years (range: $25-77$ years). The median time from SS to lymphoma diagnosis was 65.8 months (range: 0-456 months) vs 48 months (range: 0-276 months) for (A) and (UP) cohort respectively. The commonest histologic subtypes such as, MALT (mucosa associated lymphoid tissue), diffuse large B cell (DLBC) and nodal or splenic marginal zone (MZ) lymphomas were observed in similar frequencies between 
the 2 cohorts. The proportion of pSS NHLs patients with MALT lymphomas and $>1$ involved sites was significantly higher in cohort (A) compared to (UP) cohort [25/51, (49\%) vs 5/40 (12.5\%\%), $\mathrm{p}=0,0003)$ ] while extranodal localization of DLBC lymphomas was less frequent in Greek compared to Italian patients [2/12 (16.7\%) and 4/10 (40\%) respectively]. No significant differences were observed regarding anti-Ro/SSA, anti-La/ SSB, rheumatoid factors (RF) or history of parotid gland enlargement. Interestingly, no significant difference was also observed in the frequencies of serum cryoglobulinemia (without vasculitis) and C4 hypocomplementemia. Importantly, cryoglobulinemic skin vasculitis was significantly more frequent in cohort (A) than in cohort (UP) $[33 / 77$ (42,9\%) vs $12 / 63$ $(19,0 \%) \quad p=0,0027$ ] as well as bone marrow involvement by lymphoma [21/77 (27.2\%) vs $4 / 63(6.3 \%)$ respectively, $p=0,0015]$.

Conclusion: The similar lymphoma histologic subtypes, coupled with the differences in the frequency of cryoglobulinemic skin vasculitis and bone marrow involvement by lymphoma between Greek and Italian patients, suggest potential diversities in genetic background, environmental factors, disease progression and pathologic pathways in different cohorts, offering novel perspectives to study the biology of SS associated lymphomagenesis.

Disclosure of Interests: Andreas Goules: None declared, Chiara Baldini: None declared, Saviana Gandolfo: None declared, Aristea Papageorgiou: None declared, Dimitris Ziogas: None declared, Francesco Ferro: None declared, Valentina Donati: None declared, Cathryn Scott: None declared, Salvatore De Vita Grant/research support from: Roche, Pfizer, Abbvie, Novartis, BMS, MSD, Celgene, Janssen, Consultant for: Roche, Michael Voulgarelis: None declared, Athanasios Tzioufas Grant/research support from: ABBVIE, PFIZER, AMGEN, NOVARTIS, GSK

DOI: 10.1136/annrheumdis-2019-eular.5638

\section{SAT0191 LOW SOCIOECONOMIC STATUS AND HEALTH RELATED QUALITY OF LIFE IN PATIENTS WITH SYSTEMIC LUPUS ERYTHEMATOSUS}

Sebastian Herrera ${ }^{1}$, Juan Camilo Diaz-Coronado ${ }^{1,2}$, Deicy Hernandez ${ }^{1}$, Laura Betancur-Vasquez ${ }^{2}$, Ricardo Pineda.Tamayo ${ }^{1} .{ }^{1}$ Grupo de informacion clinica, Artmedica, Antioquia, Medellin, Colombia; ${ }^{2}$ Departamento medicina interna, Universidad CES, Medellin, Colombia

Background: Socioeconomic factors have been considered as possible confounding factors in the attribution of greater damage accrual in AfroCaribbean and Hispanic patients with Systemic lupus erythematosus
(SLE). Patients with SLE often experience long-term morbidity that can adversely affect their health-related quality of life (HRQoL)

Objectives: To analyze the relation between socioeconomic status, damage accrual and HRQoL

Methods: Analytic study in a cohort of SLE patients that were closely monitored in an autoimmunity program in Colombia. We stratified patients with damage (SDI $\geq 1)$ and no damage (SDI <1) and according to socioeconomic status as a surrogate value for economic income with dichotomization in low and medium/high income. We performed a non-parametric analysis of related simples of Wilcoxon in each of the dimensions of quality of life in EuroQoL $5 d$

Results: We analyzed 400 Colombian patients. Baseline median age was 49 years (15 IQR) with median age at diagnosis and disease duration of 37 years (17 IQR) and 9 years (13 IQR) respectively. There were $94 \%$ female patients and $17.3 \%$ late onset SLE. Most frequent clinical manifestations were hematological (82.8\%), mucocutaneous (75.3\%) and nephritis $(33.8 \%)$. Only $4.5 \%$ had neurological involvement. The mean SLEDA were 1.18 and 0.65 at first and second measurement respectively, in the first measurement $97.1 \%$ of the patients had a SLEDAl $\leq 4$. The mean SDI was 0.7275 at first measurement and 0.985 at the second measurement. When comparing the intervention in patients with $\mathrm{SDI} \geq 1$ there was a significative improvement in the Quotidian Activities, Pain/Discomfort, Anxiety/Depression domains, independent of economic income. In patients with medium-high income there was also a significative improvement in the mobility and personal care domains. In the no-damage groups there was only a positive impact in the Anxiety/Depression domain in a statistically significant manner, and the medium-high income subgroup had improvement in the Pain/Discomfort domain. We didn't find other statistically differences in the other domains. Low economic income seems to exert a negative influence in the different $H R Q$ oL domains with independence regarding treatment strategy, specially in patients with no damage accrual. In patients with higher income and damage accrual the opposite seems to appear, which could be related with a better ability or resources to cope with the consequences of the disease

Conclusion: In Colombian patients with SLE, socioeconomic status (as a reflection of income) might be related with HRQoL. This relationship could be influenced by damage accrual

\section{REFERENCE}

[1] Panopalis P, Petri M, Manzi S, Isenberg DA, Gordon C, Senecal JL, et al, and the Tri-Nation Study Group. The systemic lupus erythematosus TriNation study: cumulative indirect costs. Arthritis Rheum 2007;57:64-70

Disclosure of Interests: None declared

DOI: 10.1136/annrheumdis-2019-eular.6528

\begin{tabular}{|c|c|c|c|c|c|c|c|c|c|c|c|c|}
\hline & \multicolumn{6}{|c|}{ Damage present } & \multicolumn{6}{|c|}{ Damage absent } \\
\hline & \multicolumn{2}{|l|}{ Low incoming } & & \multicolumn{3}{|c|}{ Mid -high incoming } & \multicolumn{4}{|c|}{ Low incoming } & \multicolumn{2}{|c|}{ Mid -high incoming } \\
\hline & $\begin{array}{l}\text { Initial } \\
(\%)\end{array}$ & $\begin{array}{c}\text { Final } \\
(\%)\end{array}$ & p Value ${ }^{\dagger}$ & $\begin{array}{c}\text { Initial } \\
(\%)\end{array}$ & $\begin{array}{c}\text { Final } \\
(\%)\end{array}$ & p Value ${ }^{\dagger}$ & $\begin{array}{c}\text { Initial } \\
(\%)\end{array}$ & $\begin{array}{c}\text { Final } \\
(\%)\end{array}$ & p Value ${ }^{\dagger}$ & $\begin{array}{c}\text { Initial } \\
(\%)\end{array}$ & $\begin{array}{c}\text { Final } \\
(\%)\end{array}$ & p Value \\
\hline Mobility & 51 & 55 & 0,4 & 56,6 & 72,3 & 0,004 & 54,3 & 60,3 & 0,35 & 59,2 & 68 & 0,13 \\
\hline 1 & 48 & 45 & & 42,2 & 27,7 & & 44,8 & 37,9 & & 40,8 & 32 & \\
\hline 2 & 1 & 0 & & 1,2 & 0 & & 0,9 & 1,7 & & 0 & 0 & \\
\hline \multicolumn{13}{|l|}{3} \\
\hline Personal Care & 72 & 76 & 0,35 & 73,5 & 84,3 & 0,016 & 72,4 & 76,7 & 0,5 & 78,8 & 79,8 & 0,85 \\
\hline 1 & 27,1 & 23 & & 24,1 & 15,7 & & 26,7 & 21,6 & & 21,2 & 20,2 & \\
\hline 2 & 1 & 0 & & 2,4 & 0 & & 0,9 & 1,7 & & 0 & 0 & \\
\hline \multicolumn{13}{|l|}{3} \\
\hline Quotidian & 51,5 & 67 & 0,005 & 59,8 & 73,2 & 0,03 & 60,3 & 62,9 & 0,7 & 65 & 68,9 & 0,5 \\
\hline Activities & 44,3 & 33 & & 36,6 & 25,6 & & 38,8 & 31,9 & & 34 & 30,1 & \\
\hline 1 & 4,1 & 0 & & 3,7 & 1,2 & & 0,9 & 5,2 & & 1 & 1 & \\
\hline \multicolumn{13}{|l|}{2} \\
\hline \multicolumn{13}{|l|}{3} \\
\hline Pain/Discomfort & 34 & 38,1 & 0,008 & 30,1 & 44,6 & 0,003 & 37,9 & 30,2 & 0,5 & 23,1 & 40,4 & 0,002 \\
\hline 1 & 39,2 & 53,6 & & 50,6 & 49,4 & & 41,4 & 52,6 & & 53,8 & 47,1 & \\
\hline 2 & 26,8 & 8,2 & & 19,3 & 6 & & 20,7 & 17,2 & & 23,1 & 12,5 & \\
\hline \multicolumn{13}{|c|}{3} \\
\hline Anxiety/ & 51 & 70,8 & 0,001 & 61 & 79,3 & 0,001 & 51,3 & 66,4 & 0,01 & 53,9 & 73,5 & 0,001 \\
\hline Depression & 32,3 & 22 & & 26,8 & 18,3 & & 35,4 & 27,4 & & 32,4 & 23,5 & \\
\hline 1 & 16,7 & 7,2 & & 12,2 & 2,4 & & 13,3 & 6,2 & & 13,7 & 2,9 & \\
\hline \multicolumn{13}{|c|}{2} \\
\hline 3 & & & & & & & & & & & & \\
\hline
\end{tabular}

